\title{
Intracellular Magnetic Labeling of Lymphocytes for In Vivo Trafficking Studies
}

BioTechniques 24:642-651 (April 1998)

\author{
U. Schoepf, E.M. Marecos, \\ R.J. Melder, R.K. Jain and \\ R. Weissleder \\ Massachusetts General Hospital \\ and Harvard Medical School, \\ Boston, MA, USA
}

\begin{abstract}
Lymphocyte adhesion and trafficking is difficult to observe in vivo over time. We used magnetic resonance imaging (MRI) to identify magnetically labeled lymphocytes in phantom experiments and in tissue. A method of lymphocyte labeling was developed that is based on fluid-phase endocytosis of nanometer-sized biocompatible superparamagnetic particles. The maximum cell uptake in culture was $0.11 \mathrm{ng} F$ Fe/cell corresponding to $5 \times 10^{6}$ particles/lymphocyte. Cells stably retained the label and were fully viable for at least 3 days. Labeled lymphocytes showed adhesion to human endothelial cells similar to unlabeled cells, indicating no effect of labeling on cell surface expression of adhesion proteins. No particle-mediated cytotoxicity could be observed. The detection threshold of MRI for detecting labeled lymphocytes in the current study was $2.5 \times 10^{6}$ cells $/ 30 \mu \mathrm{L}$ sampling volume. Following intravenous injection of labeled lymphocytes into rats, cells accumulated in spleen, lymph nodes and liver with a similar bio-distribution as unlabeled cells. Lymphocyte accumulation in the spleen resulted in MRI signal intensity changes readily detectable by MRI. These findings suggest that intracellular lymphocyte labeling with superparamagnetic particles is feasible, does not alter the viability or tissue distribution of labeled cells and allows the detection of labeled lymphocytes by $M R I$.
\end{abstract}

\section{INTRODUCTION}

Key events in mammalian lymphocyte adhesion and trafficking in vivo are difficult to observe because there exist no high-resolution imaging methods that allow one to follow lymphocyte populations. If adequate tracer methods were developed, they would be widely applicable for studying natural killer cell adhesion in tumors (7) transplant rejection, infectious diseases such as AIDS, lymphocyte homing to lymph nodes (17) or development of cell-based drug carriers and immunotherapy (23).

A variety of techniques have been used to image lymphocyte distribution, including planar scintigraphy (14), single photon emission tomography (SPECT) and positron emission tomography $(\mathrm{PET})(7,8)$. Although all three techniques have an exquisite sensitivity in detecting labeled cells, their spatial resolution is limited $(\mathrm{cm})$, radiotoxicity to labeled cells has been described $(2,3)$ and the method can usually not be repeated to study trafficking over time because of decay of the radioactive label. High-resolution magnetic resonance imaging (MRI) has recently been used to detect submillimeter organ systems and even cells (5). To perform cell-trafficking studies by MRI, an MRI cell tracer is required that must: $(i)$ induce an MR signal characteristically different from the rest of the sample, (ii) remain in the originally labeled cells during the length of the study and (iii) be physiologically inert. Although lymphocytes have been surface-labeled with magnetic beads (1), such modifications usually alter adhesion characteristics and biological properties of labeled cells.

We have previously observed that certain cells (tumor cells, macrophages or neuronal cells) can be efficiently labeled intracellularly with dextran-coated monocrystalline iron oxide nanoparticles (MION) exploiting fluid-phase endocytosis of particles in culture (16). Other investigators have also shown that $\mathrm{T}$ lymphocytes can be magnetically labeled and detected by MRI $(21,22)$. In the current study, we extend prior observations to investigate the feasibility of intracellular magnetic labeling of lymphocytes. Our results show that lymphocytes can be efficiently labeled through fluid-phase endocytosis and that this procedure does not alter viability or functional characteristics of labeled cells.

\section{MATERIALS AND METHODS}

\section{Synthesis of MION}

The generic synthesis of MION and its physicochemical properties have been described previously $(15,16)$. Synthesis and MION modification in this study were modified as follows. Over a period of $2 \mathrm{~h}, 155 \mathrm{~g}$ of $512 \mathrm{~B}$ dextran (mol wt $11 \mathrm{kDa}$; Pharmacia Biotech, Uppsala, Sweden) were distilled in 300 $\mathrm{mL}$ of distilled (d) $\mathrm{H}_{2} \mathrm{O}$. A fresh iron solution was then prepared by dissolving $10.5 \mathrm{~g}$ of ferric chloride hexahydrate and $3.9 \mathrm{~g}$ of ferrous chloride tetrahydrate in $20 \mathrm{~mL}$ of $\mathrm{dH}_{2} \mathrm{O}$, which was added to the dextran solution (all chemical supplies except dextran were from Sigma Chemical, St. Louis, MO, USA). Chilled, concentrated ammonium hydroxide was then added dropwise to the iron-dextran solution until $\mathrm{pH}$ was 10.0. The solution was then heated in a water bath to $70^{\circ} \mathrm{C}$ for $45 \mathrm{~min}$ and allowed to cool to $20^{\circ} \mathrm{C}$ overnight. The remaining 
Table 1. Uptake of MION into Lymphocytes Isolated from Different Source Tissues and Species (ng Fe MION/106 Cells at Standard Incubation Conditions)

\begin{tabular}{|lccc|}
\hline & Rat & Mouse & Human \\
\hline Spleen & $19.8 \pm 1.3$ & $18.7 \pm 0.1$ & NA \\
Lymph node & $11.5 \pm 4.3$ & $19.1 \pm 0.3$ & NA \\
Thymus & $4.5 \pm 0.7$ & $5.8 \pm 1.1$ & NA \\
Blood & $8.7 \pm 1.4$ & $8.3 \pm 6.9$ & $27.9 \pm 3.6$ \\
\hline
\end{tabular}

free dextran was removed by diafiltration using 30-kDa hollow fiber cartridges (Amicon ${ }^{\circledR}$ H1P30-43; Millipore, Bedford, MA, USA). From this stock solution, MION was recovered by size-fractionation ultrafiltration using hollow-fiber membrane cartridges with $0.1-\mu \mathrm{m}$ pore size (Amicon H1MP0143; Millipore). The final product was concentrated with an Amicon H1P3043 filter (Millipore) and stored in 0.075 $\mathrm{M}$ sodium citrate at $4^{\circ} \mathrm{C}$ until used. MION samples were radiolabeled with 125I for the purpose of tracing them during cell uptake studies as previously described (16). MION was also labeled with rhodamine for fluorescence microscopy experiments (13).

\section{MION Labeling of Lymphocytes}

To compare the uptake of MION by

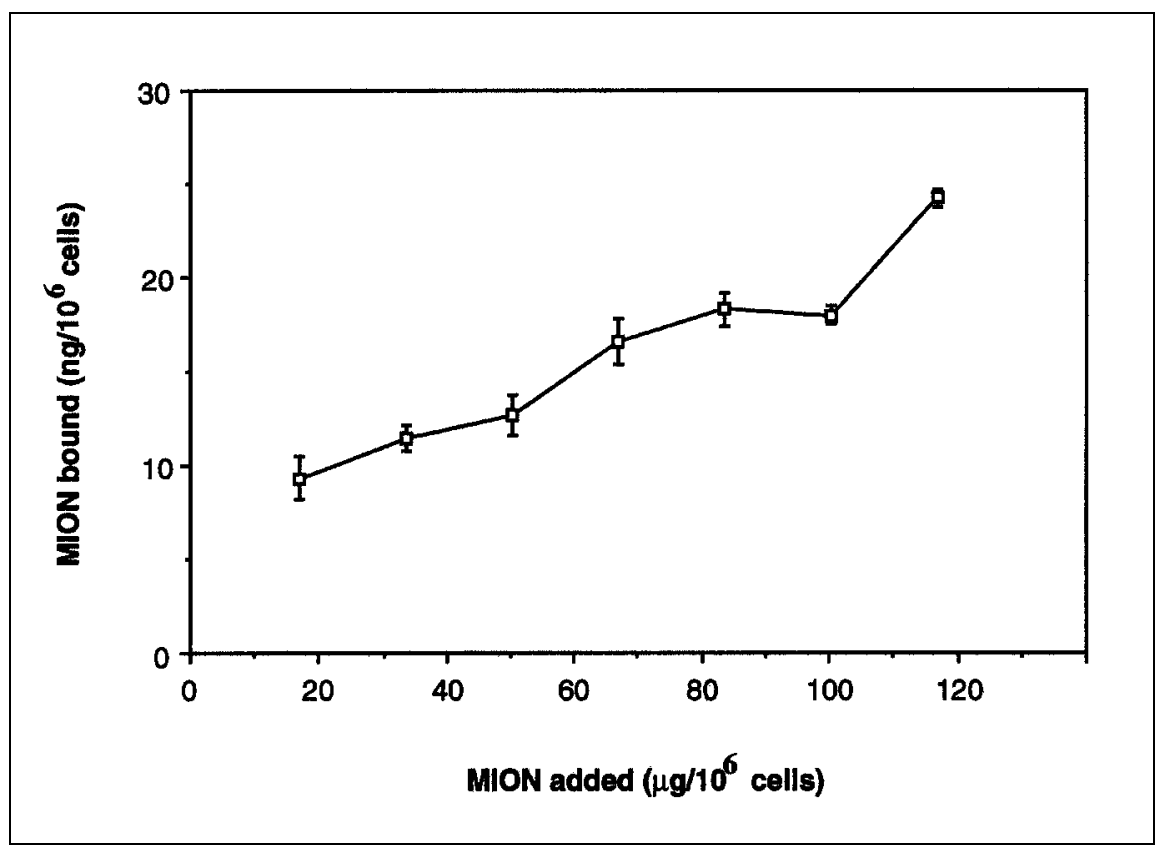

Figure 1. Effect of MION concentration in the labeling medium on lymphocyte uptake (incubation time $2 \mathbf{~ h}$, mouse spleen lymphocytes). Higher amounts of the tracer added results in higher internalization. centrifugation, erythrocytes were lysed by resuspending the cell pellet in $0.83 \%$ ammonium chloride in distilled water. Cells were washed again and incubated in RPMI 1640 supplemented with $10 \%$ FBS in $25-\mathrm{cm}^{2}$ tissue culture flasks (Falcon ${ }^{\circledR}$; Becton Dickinson Labware, Bedford, MA, USA) at $37^{\circ} \mathrm{C}$ in a $\mathrm{CO}_{2}$ atmosphere. To remove the majority of the monocyte/macrophage population, the nonadherent cell population was transferred into a new flask after $1 \mathrm{~h}$ and counted with a hemocytometer (Fisher Scientific, Pittsburgh, PA, USA). This method yielded a cell population containing about $95 \%$ lymphocytes, as determined by morphology. Blood lymphocytes were isolated using a Ficoll ${ }^{\circledR}$ gradient (Histopaque-1077; Sigma Chemical). Blood lymphocytes were also obtained from a human donor to compare MION uptake by animal and human lymphocytes. The labeling procedure described above was modified in additional experiments to determine: $(i)$ the optimal MION concentration for labeling, (ii) the optimal incubation time and cell viability after labeling and (iii) MION retention as a function of time. For these experiments, the variables were changed as shown in Figures 1-4.

To determine the amount of magnetic label associated with cells, a simple cell-binding assay was utilized. The standard labeling procedure included incubation of $3 \times 10^{6}$ cells with $250 \mu \mathrm{g}$ $125 \mathrm{I}-\mathrm{MION}$ for $2 \mathrm{~h}$, followed by extensive washing. Cells were placed into 5-mL polystyrene tissue culture tubes (Falcon; Becton Dickinson), in $0.5 \mathrm{~mL}$ of RPMI 1640 (Cellgro; Mediatech) supplemented with $10 \%$ FBS, and freshly prepared iso-osmotic MION solution was added. Cells were incubated at $37^{\circ} \mathrm{C}$ in a humidified $\mathrm{CO}_{2}$ atmosphere and then washed 3 times with 1 mL of Hanks' balanced salt solution (HBSS; Cellgro; Mediatech) underlayed with $1 \mathrm{~mL}$ of $40 \%$ Histopaque1077 in HBSS. The number of viable lymphocytes was determined by the trypan blue stain exclusion. After the final centrifugation and aspiration of the supernatant, cell pellets were counted in a gamma counter (Model 1282 Compugamma CS; LKB Wallac, Turku, Finland). Cell uptake was calculated by determining cell count per tube scaled to 
the number of cells. All experiments were performed at least in triplicate.

\section{Cytotoxicity Assay}

A cytotoxicity assay (CytoTox 96 ${ }^{\circledR}$; Promega, Madison, WI, USA) was used to determine whether MION incorporation would be toxic to lymphocytes. The assay is a colorimetric assay that quantitatively measures cytosolic lactate dehydrogenase (LDH) release upon cell lysis by enzymatic conversion of a tetrazolium salt into a red formazan product. Briefly, $2 \times 10^{6} \mathrm{MION}$ labeled or unlabeled mouse spleen lymphocytes in $200 \mu \mathrm{L}$ medium were incubated with medium or lysis solution $\left(20 \mu \mathrm{L} 9 \%\right.$ Triton $\left.^{\circledR} \mathrm{X}-100\right)$ for 30 min. Fifty-microliter aliquots were then mixed with the substrate mixture, incubated for another $30 \mathrm{~min}$ and absorbance was determined at $490 \mathrm{~nm}$. All experiments were carried out in quadruplicate.

\section{Cell Adhesion Assay}

To determine whether MION labeling affects the cell-surface expression of adhesion molecules, a lymphocytes adhesion assay to human umbilical vein endothelial cells (HUVEC) was performed (9). HUVEC cultures obtained from a pooled cord harvest were maintained in culture medium (Clonetics, San Diego, CA, USA) supplemented with $10 \%$ fetal calf serum (FCS). Monolayers were grown on $3 \times 1.5$-in. glass slides (Fisher Scientific), coated with fibronectin and were used within $48 \mathrm{~h}$ of seeding. Interaction of MIONlabeled or unlabeled human lymphocytes with HUVEC was tested in a parallel flow chamber, which permits quantification of cell adhesion under controlled conditions of flow rate, shear stress and cell flux (9). The bulk cell concentration was fixed at $2 \times 10^{6}$ cells/mL for each cell suspension, and the cumulative bound cell density was determined in at least five field at 1 dyne $/ \mathrm{cm}^{2}$ shear stress.

\section{Fluorescence Microscopy}

Fluorescence microscopy was used to confirm that MION labeling was truly intracellular. Lymphocytes were washed 5 times with Dulbecco's modified Eagle medium (DMEM; Cellgro; Mediatech) lacking FBS and phenol red. Excess media were aspirated off, and cells were then incubated for 15-60 min with rhodaminated MION in DMEM, supplemented with $10 \%$ FBS and $4 \mathrm{mM} \mathrm{L-glutamine} \mathrm{at} 37^{\circ} \mathrm{C}$ in a $\mathrm{CO}_{2}$ atmosphere. Fluorescent MION was then removed, cells were washed repeatedly in DMEM and mounted in an observation chamber. Cells were examined with an inverted fluorescence microscope (Axiovert ${ }^{\mathrm{TM}}$ 100TV; Carl Zeiss, Wetzlar, Germany) equipped with a rhodamine filter set (Omega Optical, Brattleboro, VT, USA), an intensified charge-coupled device (CCD) video camera (Model C2400-88; Hamamatsu Photonics K.K., Hamamatsu, Japan), a videocassette recorder (Model AG-6500; Panasonic, Secaucus, NJ, USA) and a video monitor (Model PVM1343MD; Sony, Tokyo, Japan). Cells were observed in the rhodamine channel and by brightfield microscopy. Captured images were transferred to a Power Macintosh ${ }^{\circledR}$ 7600/120 computer (Apple Computer, Cupertino, CA, USA).

\section{Bio-distribution of MION-Labeled Lymphocytes}

Splenic lymphocytes were obtained from two donor Fisher rats (Charles
River). All animal experiments were performed in accordance with the national animal care guidelines. One batch of lymphocytes was labeled with MION as described above while the second batch remained unlabeled. To make lymphocytes in both batches traceable in vivo, cells were also labeled with ${ }^{111}$ In-oxine (3). Briefly, ${ }^{111} \mathrm{In}^{-\mathrm{Cl}_{3}}$ (NEN Life Science Products, Boston, MA, USA) was added to $0.05 \mathrm{~mL}$ of 8hydroxyquinoline $(1.0 \mathrm{mg} / \mathrm{mL}$ in ethanol; Sigma Chemical), $0.2 \mu \mathrm{L} \mathrm{Na}$ acetate $(250 \mathrm{mg} / \mathrm{mL})$ and $1.0 \mathrm{~mL}$ of $\mathrm{MeCl}_{2}$. After mixing, the watery layer was discarded and the chloroform evaporated under an argon gas stream. The ${ }^{111}$ In-oxine chelate was redissolved in ethanol and slowly added to the tube containing the cells. After a 25-min incubation at $37^{\circ} \mathrm{C}$, cells were washed twice over a gradient of $40 \%$ Histopaque in phosphate-buffered saline (PBS) and once in PBS alone. Lymphocytes were resuspended in PBS and injected into the tail veins of ten rats. Twelve hours after injection, animals were sacrificed under general anesthesia by lethal intravenous injection of sodium pentobarbital. Samples of spleen, lymph nodes, thymus, blood, bone, heart, intestine, liver, lung, muscle and fat were excised and weighed, and radioactivity was measured using a well-type gamma counter (Model 1282 Compugamma CS; LKB Wallac). Ali-

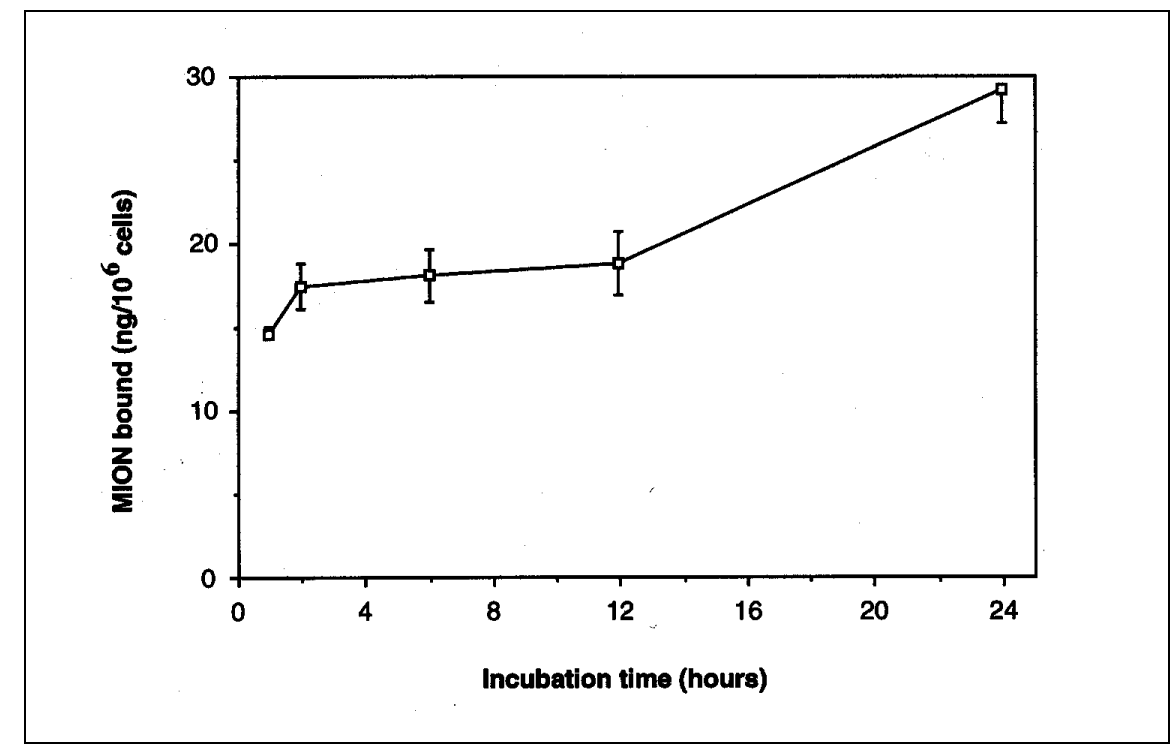

Figure 2. Effect of incubation time on MION uptake by mouse spleen lymphocytes: longer incubation times result in higher internalization. 
quots of cell suspensions were counted simultaneously to correct for radioactivity decay and to calculate the dose in each organ. Bio-distribution results were expressed as percentage of the injected dose per gram of tissue (\% ID/g).

\section{MR Imaging}

Two separate imaging experiments were performed: $(i)$ imaging of labeled lymphocytes in culture and (ii) imaging of animal tissues following IV injection of labeled lymphocytes. The phantoms were specifically prepared to determine the detection threshold of MION-labeled lymphocytes. Cell pellets $(30 \mu \mathrm{L}$ containing either $1,2.5,5$ or $10 \times 10^{6}$ of MION-labeled lymphocytes were placed in $1 \%$ low-melting agarose [Bio-Rad, Hercules, CA, USA]) to avoid air-induced susceptibility artifacts. Nonlabeled lymphocytes $\left(10^{7}\right.$ cells/pellet) served as controls. MR imaging was performed using a $1.5 \mathrm{~T}$ Superconducting Magnet (Signa 5.0; GE Medical Systems, Milwaukee, WI, USA) with a 5-in. surface coil. The imaging protocol consisted of coronal T1-weighted, spin echo (SE) and T2weighted, steady-state free precession (SSFP) or dual-echo, fast spin echo (FSE) pulse sequences. The timing parameters for these sequences were $\mathrm{SE}$ 300/15 (TR/TE), 3D SSFP 50/90/60 (TR/TE/FA) and FS 2000/34, 102 (TR/TE1/TE2). Slice thickness was 3 $\mathrm{mm}$ for SE and $0.7 \mathrm{~mm}$ for SSFP se-

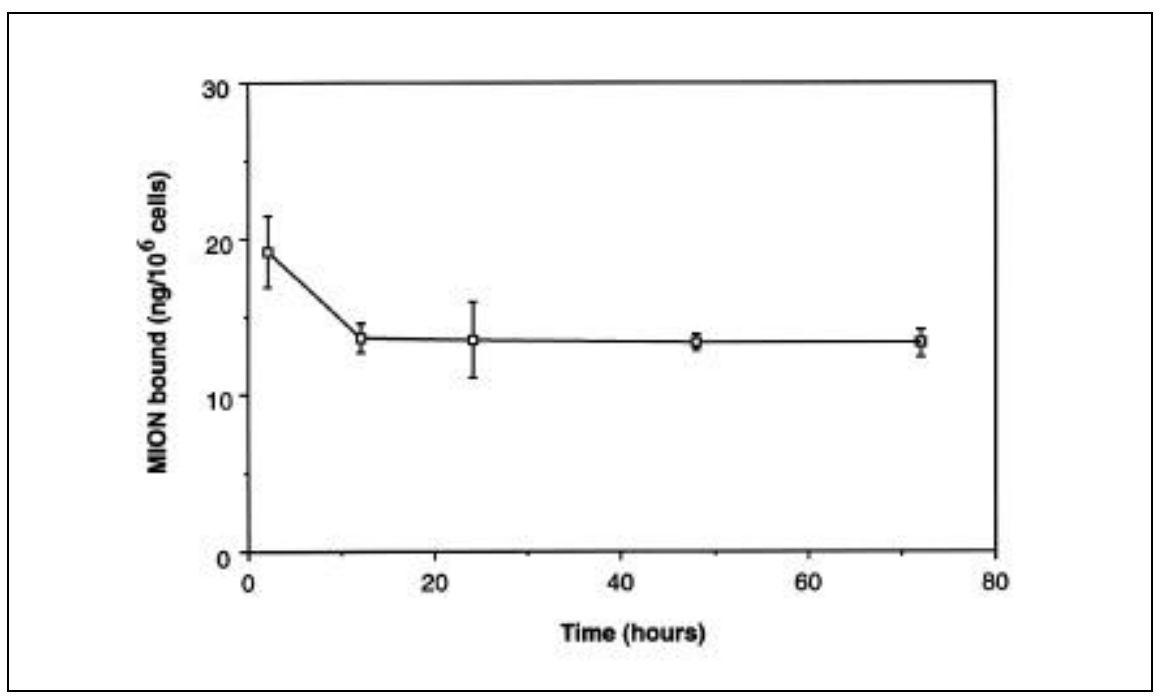

Figure 3. MION retention by mouse spleen lymphocytes over time (incubation time $2 \mathrm{~h}, 250 \mu \mathrm{g}$ MION). Once a steady state is reached, the magnetic tracer is stably retained within lymphocytes.

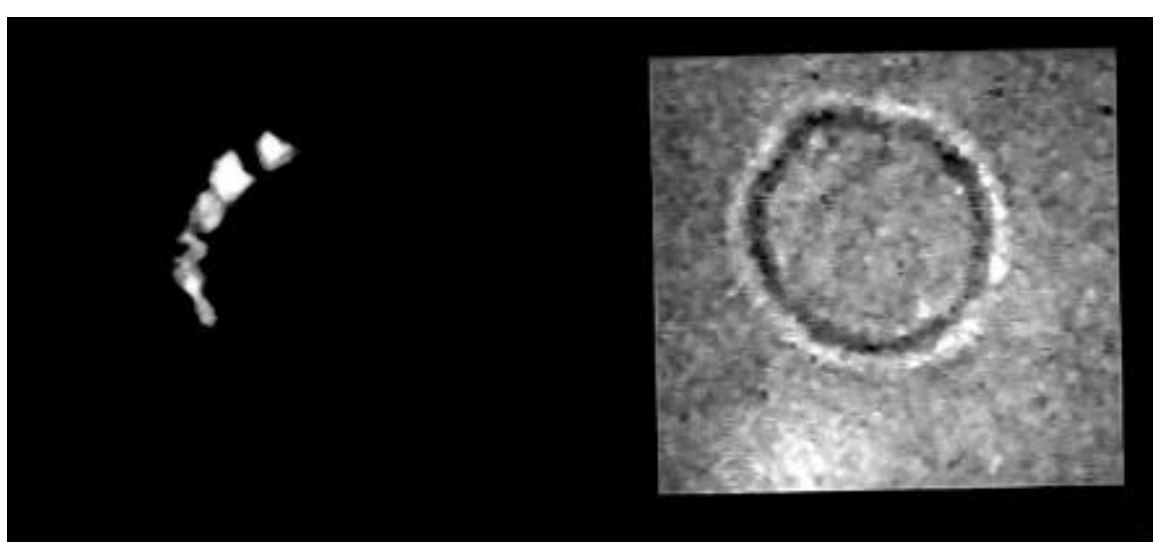

Figure 4. Fluorescence microscopy (left) and bright-field microscopy (right) of a mouse spleen lymphocyte 30 min after incubation with rhodaminated MION. The tracer is contained within cytoplasmatic vesicles, sparing the nucleus. No surface staining could be observed.

quences. The field of view (FOV) was $12 \times 12 \mathrm{~cm}$, the imaging matrix was $256 \times 128$ and the number of acquisitions was $2-4$.

To determine whether MION-labeled lymphocytes would be detectable in an intact organ, $10^{8}$ 125I-MION-labeled spleen lymphocytes were injected into mice, and their spleens were removed either 1 or $48 \mathrm{~h}$ after injection. Spleens were embedded in a $1 \%$ agarose gel to optimize the signal uniformity and subsequently subjected to MRI. The spleen from one animal that had received the same number of unlabeled lymphocytes served as control. The MRI protocol was identical to that used for phantom experiments. The number of labeled lymphocytes that had accumulated in each spleen was determined by gamma counting.

\section{RESULTS}

\section{Labeling Efficiency}

The initially developed labeling procedure $\left(3 \times 10^{6}\right.$ lymphocytes incubated with $250 \mu \mathrm{g}$ of MION for $2 \mathrm{~h}$ ) resulted in a cellular uptake of $18 \pm 2 \mathrm{ng}$ of $\mathrm{Fe} / 10^{6}$ rodent spleen lymphocytes (mean uptake $0.02 \%$ ). This amount corresponds to approximately $8 \pm 1 \times 10^{4}$ MION particles per lymphocyte (16). Figures 1-5 illustrate the effect of different variables on cell uptake. As expected, higher tracer concentrations (Figure 1) and prolonged incubation times (Figure 2) resulted in higher tracer uptake, reaching 20-25 ng/Fe per $10^{6}$ cells. Cell uptake followed a roughly linear pattern and appeared not to be saturable in the tested ranges of concentration and incubation time, as would be expected for fluid-phase endocytosis. Lymphocytes from different tissues and donor species showed little variation in tracer uptake (Table 1), ranging from 8-22 ng Fe MION/106 cells. The magnetic tracer was most readily internalized by cells obtained from spleen and thymus. Lymph node and peripheral blood lymphocytes showed a slightly lower internalization except for human lymphocytes. Another variable with an influence on cell uptake was the cell density during the MION incubation step. When $0.6 \times 10^{6}$ lymphocytes 
instead of $3 \times 10^{6}$ lymphocytes were incubated with $250 \mu \mathrm{g}$ of $\mathrm{MION}$, cell uptake was fivefold higher per lymphocyte, presumably related to more favorable micro-environmental conditions when fewer cells are present per well. In another set of experiments, we determined tracer release following labeling. When kept in culture, labeled cells released approximately $5 \mathrm{ng}$ MION/106 cells within the first $12 \mathrm{~h}$ (Figure 3). Thereafter, the tracer was stably retained within lymphocytes.

Figure 4 shows a photomicrograph of a lymphocyte after $1 \mathrm{~h}$ of incubation with rhodaminated MION using fluorescent and bright-light microscopy. The intracellular distribution of fluorescent MION was restricted to rounded structures (vesicles) inside the cytoplasmic compartment of the cell. These vesicles occasionally indented the surface of the lymphocytes. No surface or nuclear staining could be detected. Labeling of cells with the rhodaminated tracer could be observed as early as 15 min after incubation. There was little variation in the morphology of labeled cells, with virtually all cells containing the tracer.

\section{Lymphocyte Viability and Function}

Labeling of lymphocytes did not impair the cell viability in culture (Figure $5)$. There was virtually no difference be-

Table 2. Bio-distribution (\% ID/g Tissue) of Non-MION-Labeled and MION-Labeled Rodent Splenic Lymphocytes

\begin{tabular}{|lcc|}
\hline & $\begin{array}{c}\text { Non-MION-Labeled } \\
\text { Lymphocytes }\end{array}$ & $\begin{array}{c}\text { MION-Labeled } \\
\text { Lymphocytes }\end{array}$ \\
\hline $\begin{array}{l}\text { Spleen } \\
\text { Lymph node } \\
\text { peripheral }\end{array}$ & $3.81 \pm 2.99$ & $4.19 \pm 3.09$ \\
central & $0.16 \pm 0.12$ & $0.23 \pm 0.10$ \\
Thymus & $0.23 \pm 0.19$ & $0.19 \pm 0.10$ \\
Blood & $0.19 \pm 0.10$ & $0.16 \pm 0.09$ \\
Bone & $0.42 \pm 0.39$ & $0.44 \pm 0.19$ \\
Heart & $0.13 \pm 0.06$ & $0.11 \pm 0.02$ \\
Intestine & $0.22 \pm 0.22$ & $0.22 \pm 0.09$ \\
Liver & $0.20 \pm 0.20$ & $0.29 \pm 0.12$ \\
Lung & $3.05 \pm 3.01$ & $2.49 \pm 0.75$ \\
Muscle & $0.42 \pm 0.25$ & $0.35 \pm 0.09$ \\
Fat & $0.07 \pm 0.07$ & $0.06 \pm 0.01$ \\
All cells were co-labeled with IIIIn-oxide & $0.05 \pm 0.02$ \\
\hline
\end{tabular}

tween the number of viable labeled and unlabeled cells at each given time point (Figure 5). Likewise, the LDH-based cytotoxicity assay did not show any MION-associated cytotoxicity at experimental concentrations. No differences in HUVEC adhesion of MION-labeled $(195 \pm 20$ cells $/ 10 \times$ microscopic field $)$ and unlabeled lymphocytes $(205 \pm 25$ cells/field) could be observed, indicating that the tracer labeling does not affect cell adhesion proteins.

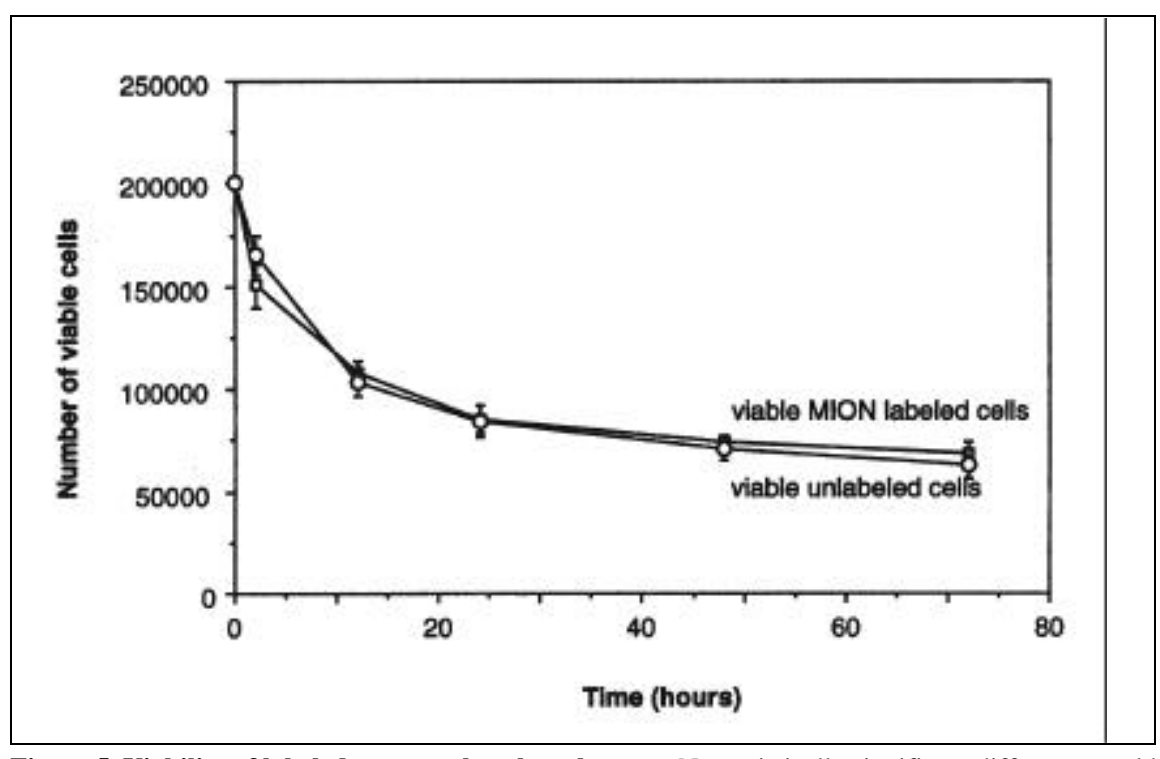

Figure 5. Viability of labeled mouse spleen lymphocytes. No statistically significant difference could be detected in the viability of isolated lymphocytes.

\section{Bio-distribution and Imaging of MION-Labeled Lymphocytes}

Table 2 compares the bio-distribu-

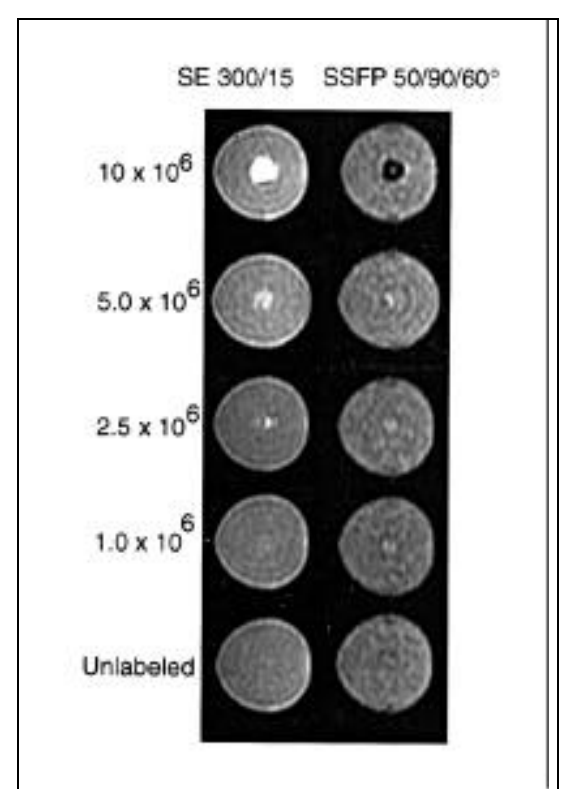

Figure 6. MRI of MION-labeled mouse spleen lymphocytes. The phantom consists of 5 individual agar wells that contained pellets of MION-labeled lymphocytes ranging from $1 \times 10^{6}$ to $10 \times$ $10^{6}$ cells and an unlabeled lymphocyte pellet (bottom). The phantom was imaged with a T1weighted spin echo (left) and T2-weighted sequence (right). Labeled cells are markedly hyperintense on SE 300/15 (T1 effect) with a detection limit of approximately $2.5 \times 10^{6}$ cells. Using the T2-weighted sequence, labeled cells show a low MR signal (T2 effect). 
tion of MION-labeled and unlabeled lymphocytes in rats $12 \mathrm{~h}$ after intravenous injection. Lymphocytes predominately accumulated in lymphatic tissues such as spleen, lymph nodes and liver. There was no significant difference in the bio-distribution of labeled and nonlabeled lymphocytes.

Figure 6 shows the effect of MION labeling on the MRI signal intensity of lymphocytes. While a pellet of nonlabeled lymphocytes had a similar signal intensity as agar on both T1- and T2-weighted images, labeled cells appeared markedly hyperintense relative to agar using the T1-weighted spin echo sequence (SE 300/15). As expected, signal intensity increased with an increasing number of cells contained within the central pellet, with a threshold of detection of about $2.5 \times 10^{6}$ labeled cells $/ 30 \mu \mathrm{L}$. Using the T2weighted SSFP sequence, MION-labeled lymphocytes appeared hypo- intense relative to agar at high concentrations (T2 effect), whereas they appeared slightly hyperintense at lower concentrations (T1 effect) with a similar detection threshold of about $2.5 \times$ $10^{6}$ cells $/ 30 \mu \mathrm{L}$.

When magnetically labeled lymphocytes were injected into mice $8 \pm 1.3 \times$ $10^{6}(1 \mathrm{~h})$ or $15 \pm 2.2 \times 10^{6}(48 \mathrm{~h})$ lymphocytes were present in the spleen, as determined by gamma counting. These labeled lymphocytes resulted in an increase in spleen signal intensity on T1and T2-weighted images, which was most pronounced at $48 \mathrm{~h}$ after IV injection of labeled cells (Figure 7).

\section{DISCUSSION}

Monocrystalline iron oxide nanoparticles labeled with dextran have been used as a tracer to visualize different molecular and physiologic events
$(13,17-19,24)$ by MRI. We had previously observed that this magnetic tracer is internalized into proliferating tumor cells by fluid-phase endocytosis (16) and hypothesized that this mechanism would also lead to internalization of nanoparticles into isolated lymphocytes. The observed uptake kinetics (roughly linear and non-saturable) seem to suggest that fluid-phase endocytosis $(4,6,10-12)$ is indeed the most likely mechanism resulting in intracellular vesicular accumulation of the tracer (Figure 6) in lymphocytes. Intracellular rather than surface labeling of lymphocytes is preferable for in vivo trafficking studies since it theoretically leaves receptors and other surface structures intact for adhesion. The intracellular pathway and biodegradation of iron oxides, labeled with dextran, within cells has been investigated $(13,16)$ and includes: (i) lysosomal breakdown, (ii) incorporation of iron 
into regulated iron pathways and (iii) degradation of dextran (20). Clinical trials attest to the safety and nontoxicity of such agents (20).

\section{Optimizing Lymphocyte Labeling}

Through optimization studies, we have adopted a labeling procedure that uses incubation of $3 \times 10^{7}$ cells in 0.5 $\mathrm{mL}$ medium with $250 \mathrm{mg}$ Fe tracer for $2 \mathrm{~h}$ followed by extensive washing. Although this protocol does not necessarily result in the highest intracellular loading possible, it represents a compromise of loading efficacy, timeliness and economical feasibility. If the method were to be scaled up to meet investigational and clinical needs, decreasing the cell density or increasing the amount of the tracer in larger incubation volumes could improve labeling up to fivefold under the experimental conditions tested, but with increased cost. Dynamic devices like flow dialysis or re-purification of the tracer may well be helpful in overcoming such shortfalls.

\section{Properties of Labeled Cells}

Our results demonstrate that MION labeling was not cytotoxic and had no measurable adverse effect on cell viability as determined by trypan blue exclusion counting (Figure 5) or cell proliferation (data not shown). Magnetically labeled cells showed similar HUVEC attachment as nonlabeled cells, suggesting that the labeling process does not interfere with cell-surface expression of adhesion molecules. Labeled cells had a bio-distribution similar to nonlabeled lymphocytes when tested in vivo (Table 2 ). This similarity is an indicator of the fact that labeling leaves the surface structure and biological functions of labeled cells intact. The bio-distribution observed in our study and other studies using different iron oxide labels $(21,22)$ suggest that homing of intracellularly labeled lymphocytes to lymphatic tissues occurs to a much higher degree than in previous studies in our laboratory in which lymphocytes had been surface-labeled.

\section{MRI of Labeled Lymphocytes}

The MRI technique is fundamentally different from optical techniques in visualizing labeled lymphocytes. In conventional MRI, the recorded signal arises from proton (hydrogen) spins of water and other hydrogenated molecules. Contrast in an MRI arises from voxel-to-voxel variation of proton concentrations and local environments such as presence of (super)paramagnetic-labeled cells that modulate T1 and $\mathrm{T} 2$ relaxation times of water. Orthogonally applied field gradient superimposed on a static magnetic field then allow spatial encoding of the MRI signal and thus 2- and 3-dimensional localization of labeled cells at high resolutions.

The detection threshold of labeled cells in phantom experiments was $2.5 \times$ $10^{6}$ cells/30 $\mu \mathrm{L}$ sampling volume in this study using a clinical imaging system. This detection threshold corresponds to approximately $50 \mathrm{ng} \mathrm{Fe} / \mathrm{sam}$ ple and is similar to that reported in vivo for other MRI applications (24). When labeled lymphocytes where injected IV, splenic tissue clearly had an altered signal intensity. Our calculations suggest that spleens of recipient animals contained approximately $8 \times$ $10^{6}$ labeled lymphocytes at $1 \mathrm{~h}$ and 1.5



Figure 7. MRI of spleens from animals who had received unlabeled (left) or MION-labeled mouse spleen lymphocytes (right). Spleens containing MION-labeled lymphocytes appear increasingly hyperintense on FSE 2000/34 and on FSE 2000/102. 
$\times 10^{7}$ cells at $48 \mathrm{~h}$ after injection. Using these numbers of detectability, one could derive the number of cells necessary to visualize, for example, natural killer cell homing to tumors (7); assuming a homing rate of about $10 \%$ of injected lymphocytes into a solid tumor of a $90-\mathrm{mL}$ volume, approximately 7.5 $\times 10^{7}$ cells would have to be injected into an experimental animal to create a detectable change in MRI signal intensity. Although these numbers appear high, there exist several approaches to increase the sensitivity in tracking superparamagnetically labeled cells in vivo. For example, the development of iron-oxide sensitive pulse sequences, different iron-oxide preparations (higher relaxivity) and higher resolution MRI are expected to improve the sensitivity of detection. Finally, selective administration of labeled cells into afferent vessels would further increase the homing rate into target organs and thus improve visualization.

\section{ACKNOWLEDGMENTS}

We are grateful and indebted to Richard Winpenny and Paul Petherick for invaluable support throughout this project, to Anna Bogdanova for performing cytotoxicity assays and to Alexei Bogdanov for inspiring discussion and comments. Supported in part by NIH Grant Nos. 2 RO1 CA 5488604A1, 5 RO1 CA 59649-04, 1 RO1 NS 35258-81 and R35 CA 56591.

\section{REFERENCES}

1.Bulte, J.W., Y. Hoekstra, R.L. Kamman, R.L. Magin, A.G. Webb, R.W. Briggs, K.G. Go, C.E. Hulstaert and S. Miltenyi. 1992. Specific MR imaging of human lymphocytes by monoclonal antibody-guided dextran-magnetite particles. Magn. Reson. Med. 25:148157.

2.Fawwaz, R., S. Oluwole, T. Wang, N. Kuromoto, C. Iga, M. Hardy and P.O. Alderson. 1985. Biodistribution of radiolabeled lymphocytes. Radiology 155:483-486.

3.Frost, P., J. Smith and H. Frost. 1978. The radiolabeling of lymphocytes and tumor cells with ${ }^{111}$ Indium. Proc. Soc. Exp. Biol. Med. 157:61-65.

4.Goud, B., C. Jouanne and J. Antoine. 1984. Reversible pinocytosis of horseradish peroxidase in lymphoid cells. Exp. Cell Res. 153:218-235.
5.Jacobs, R. and S. Fraser. 1994. Magnetic resonance microscopy of embyonic cell lineages and movements. Science 263:681-684.

6.McVey Ward, D., C. Perou, M. Lloyd and J. Kaplan. 1995. "Synchronized" endocytosis and intracellular sorting in alveolar macrophages: the early sorting endosome is a transient organelle. J. Cell Biol. 129:1229-1240.

7.Melder, R., A. Brownell, T. Shoup, G. Brownell and R. Jain. 1993. Imaging of activated natural killer cells in mice by positron emission tomography: preferential uptake in tumors. Cancer Res. 53:5867-5871.

8.Melder, R., D. Elmaleh, A. Brownell, G. Brownell and R. Jain. 1994. A method for labeling cells for positron emission tomography (PET) studies. J. Immunol. Methods 175:7987.

9.Munn, L., R. Melder and R. Jain. 1994. Analysis of cell flux in the parallel plate flow chamber: implications for cell capture studies. Biophys. J. 67:889-895.

10.Pratten, M. and J. Lloyd. 1986. Pinocytosis and phagocytosis: the effect of size of a particulate substrate on its mode of capture by rat peritoneal macrophages cultured in vitro. Biochim. Biophys. Acta. 881:307-313

11.Rabinowitz, S., H. Horstmann, S. Gordon and G. Griffiths. 1992. Immunocytochemical characterization of the endocytic and phagolysosomal compartments in peritoneal macrophages. J. Cell Biol. 116:95-112.

12.Racoosin, E. and J. Swanson. 1993 Macropinosome maturation and fusion with tubular lysosomes in macrophages. J. Cell Biol. 121:1011-1020.

13.Schulze, E., J. Ferrucci, K. Poss, L. Lapointe, A. Bogdanova and $R$. Weissleder. 1995. Cellular uptake and trafficking of a prototypical magnetic iron oxide label in vitro. Invest. Radiol. 30:604-610.

14.Thakur, M., E. Coleman, C. Mayhall and M.J. Welch. 1976. Preparation and evaluation of ${ }^{111}$ In-labeled leukocytes as an abscess imaging agent in dogs. Radiology 119:731732.

15. Weissleder, R., inventor. Monocrystalline iron oxide particles for studying biological tissues. U.S. patent 5,492,814. 1996 February 20.

16.Weissleder, R., H. Cheng, A. Bogdanova and A.J. Bogdanov. 1997. Magnetically labeled cells can be detected by MR imaging. J. Magn. Reson. Imaging 7:258-263.

17.Weissleder, R., G. Elizondo, J. Wittenberg, A. Lee, L. Josephson and T. Brady. 1990. Ultrasmall superparamagnetic iron oxide: an intravenous contrast agent for assessing lymph nodes with MR imaging. Radiology 175:494-498

18.Weissleder, R., A. Lee, B. Khaw, T. Shen and T. Brady. 1992. Antimyosin-labeled monocrystalline iron oxide allows detection of myocardial infarct; MR antibody imaging. Radiology 182:381-385.

19.Weissleder, R., P. Reimer, A. Lee, J. Wittenberg and T. Brady. 1990. MR receptor imaging: ultrasmall iron oxide particles targeted to asialoglycoprotein receptors. Am. J. Roentgenol. 155:1161-1167.

20.Weissleder, R., D.D. Stark, B.L. Engelstad, B.R. Bacon, C.C. Compton, D.L. White, P. Jacobs and J. Lewis. 1989. Superparamag- netic iron oxide: pharmacokinetics and toxicicty. Am. J. Roentgenol. 152:167-173.

21.Yeh, T., W. Zhang, S. Ildstad and C. Ho. 1995. In vivo dynamic MRI tracking of rat Tcells labeled with superparamagnetic iron-oxide particles. Magn. Reson. Med. 33:200-208.

22.Yeh, T., W. Zhang, S. Ildstad and C. Ho. 1993. Intracellular labeling of T-cells with superparamagnetic contrast agents. Magn. Reson. Med. 30:617-625.

23.Zhu, H., R. Melder, L. Baxter and R. Jain. 1996. Physiologically based kinetic model of effector cell biodistribution in mammals: implications for adoptive immunotherapy. Cancer Res. 56:3771-3781.

24.Zimmer, C., R. Weissleder, K. Poss, A. Bogdanova, S.J. Wright and W.S. Enochs. 1995. MR imaging of phagocytosis in experimental gliomas. Radiology 197:533-538.

Received 2 July 1997; accepted 2 October 1997.

Address correspondence to:

Dr. Ralph Weissleder

Center for Molecular Imaging Research

Massachusetts General Hospital

149 13th St., Rm. 5403

Boston, MA 02114, USA

Internet:weissleder@helix.mgh.harvard.edu 